Article

\title{
Psychasthenia Studio and the Gamification of Contemporary Culture
}

\author{
Victoria Szabo \\ Art, Art History \& Visual Studies, Duke University, Durham, NC 27708, USA; E-Mail: ves4@duke.edu
}

Submitted: 7 January 2018 | Accepted: 2 April 2018 | Published: 7 June 2018

\begin{abstract}
What does it mean to say that Games Matter within a new media art context? Conversely, what contributions can artists and scholars exploring the medium make to the cultural conversation around their use and meaning? This contribution highlights the ways in which our interdisciplinary art collective, Psychasthenia Studio, has addressed the cultural effects of games and gamification as they have evolved over the last decade, using a series of videogame art projects as the medium of expression and critique. As Mary Flanagan (2009) suggested in Critical Play, "games carry beliefs within their representation systems and mechanics" (p. 4). Through their thematic content and interaction design, the three videogames developed by us in the interdisciplinary Psychasthenia Studio between 2009-2017 draw attention to those beliefs as they exist not only in the games themselves, but also more broadly in an increasingly gamified contemporary culture. Psychasthenia Studio simultaneously intervenes in the discussion around games in society and pushes the boundaries of what constitutes new media art practice today. By playing the Psychasthenia games, our hope is that users both co-author and witness their own participation in the system.
\end{abstract}

\section{Keywords}

activist games; critical play; game studies; gamification; installation art; new media; psychology; subversion; videogames

Issue

This article is part of the issue "Games Matter? Current Theories and Studies on Digital Games", edited by Julia Kneer (Erasmus University Rotterdam, The Netherlands) and Ruud Jacobs (University of Twente, The Netherlands).

(C) 2018 by the author; licensee Cogitatio (Lisbon, Portugal). This article is licensed under a Creative Commons Attribution 4.0 International License (CC BY).

\section{Introduction}

What does it mean to say that Games Matter within a new media art context? Conversely, what contributions can artists and scholars exploring the medium make to the cultural conversation around their use and meaning? The cultural conversation around games has moved beyond concerns over their anti-social effects or status as mere entertainment and explores their value and impact. Within that framework, this contribution highlights the ways in which our interdisciplinary art collective, Psychasthenia Studio, has addressed the cultural effects of games and gamification as they have evolved over the last decade, using a series of videogame art projects as the medium of expression and critique. As Mary Flanagan (2009) suggested in Critical Play: Radical Game Design, "games carry beliefs within their representation systems and mechanics" (p. 4). Through their thematic content and interaction design, the three videogames we have developed in Psychasthenia Studio between 2009-2017 draw attention to those beliefs as they exist not only in the games themselves, but also more broadly in an increasingly gamified contemporary culture. In our games we strive to show the effects that gamification has on personal identity, agency, and self-definition, and the extent to which the avatar identities we produce through gamified personal and professional interactions are dependent upon pre-existing structures of meaning and value. By taking advantage of the affordances of the game engine to communicate its ideas, Psychasthenia Studio simultaneously intervenes in the discussion around games in society and pushes the boundaries of what constitutes new media art practice today. By playing the Psychasthenia games, our hope is that users both co-author and witness their own participation in the system.

\section{Games, Gamification, and Contemporary Culture}

In 2005 Jesper Juul concluded his study of the Half-real: Video games between real worlds and fictional worlds by 
saying that though "the fictional worlds of games are optional, subjective, and not real, they play a key role in video games. The player navigates these two levels, playing video games in the half-real zone between the fiction and the rules" (p. 202). More than a decade later, the fictional world of games is converging with the real.

Gamification, or the process of introducing game elements into real world activities, has also taken hold in business, industry, and education. Researchers in the social sciences and education take an analytical approach to games and gamification, studying the reward structures of games themselves, or the impact of games on cognition, learning, attention, productivity, and motivation. Points systems, badges, and curation of competitive communities online had already emerged by the early 2010s, bolstered by books discussing the benefit of videogames and gamification to encourage achievement. Karl M. Kapp's The Gamification Of Learning and Instruction: Game-Based Methods and Strategies for Training And Education (2012) centered on the creation of engagement. The MacArthur Foundation, Mozilla, and the Bill and Melinda Gates Foundation funded a 2011-13 Digital Media and Learning competition focused on badges for learning; Mozilla subsequently set up a micro-credentialing system that continues to be adopted (HASTAC; Mozilla). This gamification processes also extends into the creation of individual identities online through social media and the open-ended quest for more hearts and likes and followers. Apps like FourSquare and FitBit build in competition as a matter of course. Jane McGonigal helped move gamification research into everyday life in celebratory fashion though her influential book Reality Is Broken: Why Games Make Us Better and How They Can Change the World (2011) and her researchdriven follow-up, SuperBetter: A Revolutionary Approach to Getting Stronger, Happier, Braver, and More Resilient (2015). In both works she argues the value of gamifying everyday life through points systems, competitions, and quest goals.

During this same period, critical game studies and new media art games have evolved in parallel, and at times in dialog with, these developments, offering critiques of the instrumental use of games, while at the same time exploring the emerging medium's expressive potential. The term "gamification" often implies a critique of an increasingly pervasive phenomenon, "the use of game design elements in non-game contexts" (Deterding, Dixon, Khaled, \& Nacke, 2011, p. 10). The darker sides of this development, as noted earlier, are what the Psychasthenia Studio team intentionally parodies. This follows upon a more general "ludification of culture" that we expose in our creations (Raessens, 2006, p. 52). Yet, as noted by the editors of The Gameful World: Approaches, Issues, Applications, gamification also represents "the most recent and visible instantiation of the interpenetration of games with everyday life (Walz \& Deterding, 2014, p. 6). Games themselves are not new, nor is their instrumental use for education and training, advertising, art, or entertainment. We are experiencing a cultural moment in which they are highly visible, in part because new technologies are making it more possible for a wider range of actors to participate in their creation and use.

Some critics engaged with the discussion over games and gamification, are also hybrid practitioner-critics. Jane McGonigal, lan Bogost, Noah Wardruip-Fruin, and Mary Flanagan, among others, both study and produce games of various kinds as a natural extension and complement to their written work. This ability to move between the critical and creative realms lends an extra dimension of insider understanding to their critiques of games and gamification. Bogost is known both for explaining "Why gamification is bullshit" in the context of an increasingly diffuse set of business practices adopting game-like attributes, and for his own compelling series of Persuasive Games, like the Killer Flu game he distinguishes from the pseudo-game hype of corporate consultants (Bogost, 2014, p. 70). In addition, activist games like Darfur is Dying by Take Action Games is one of many at Games for Change (from interFUEL, 2006), which strives to educate through meaningful gameplay. Meanwhile, the Radical Games of Molleindustria, which describes itself as producing "artisanal remedies to the idiocy of mainstream entertainment in the form of free, shortform, online games, include "simulations" like the satirical McDonalds and Oligarchy games (Pedercini).

The creation of complex, 3D immersive games is becoming increasingly accessible as a medium of expression for artists and critics. Videogame play capture and machinima (movies produced from game footage) are not new, as Henry Lowood and Michael Nitsche and others have noted (Lowood \& Nitsche, 2014), and mods and hacks have enabled gamers to change up in-game experiences in ways that are increasingly anticipated by the game companies. Beyond that, as videogame platforms like Unity3D and Unreal have become more accessible and affordable, the independent game world continues to increase in size and diversity. The huge Valve Corporation Steam game distribution platform, for example, provides a clearinghouse for distributing a wide range of games, including those by independent developers, and, importantly, older titles (STEAM Store). A number of new media artists now use videogame engines behind the scenes to fuel their installation art, and immersive, 3D games are also of growing importance in the cultural heritage and museum contexts. Such uses bring up questions related to simulation, truthfulness, representativeness, among others. This does not touch upon the convergence of social media and virtual reality happening with Facebook's acquisition of Oculus Rift, and Apple and Google's forays into social augmented reality. In short, complex, immersive gamified experience design that blurs the boundaries between the real and the virtual is an important growth area for the intersection of social media with game technologies, potentially leading to the further gamification of everyday life (Graham, 2017; Kaplan, 2015). 
This combination of broad cultural interest, a rich critical landscape, and increasingly accessible authoring technologies provides a great opportunity to new media artists interested in the medium's potential. John Sharp described the intersection of the game and art worlds in Works of Game (2015), issuing an implicit challenge:

Game art (art made from games) uses games for the thin aesthetics of symbolic expression in service of the thick aesthetics of conceptual exploration. Artgames take a more conservative approach of emphasizing representational expression in a thick way, at the same time that they thinly explore the conceptually and critically focused aesthetics of contemporary art. But what happens when an artist combines the thick aesthetics of both communities to produce an artists' game? (Sharp, 2015, p. 78)

Sharp distinguishes between game art, which uses game tools art artistic effects, and artgames, which are conceptually interesting from the game perspective but which to the art community are less interesting for their "emphasis on craft and medium" (p. 78). The aspirational third term in his analysis is the artist's game. The artist's game, Sharp suggests, is a game that both takes full advantage of the technological affordances of the medium and engages in the richness of conceptual art. By producing work that is as much about the medium and its potential as it utilizes its effects, with the Psychasthenia series we attempt to create artist's games. We push into the thick aesthetics of game-world conventions and interactions, while at the same time exploring new ways to aggregate disparate visual elements in 3D, to introduce non-representational visuals into mundane, relatively low-poly game spaces, and to point out the gamified nature of the social phenomena we parody.

Artists's games, Sharp suggests, are often collaboratively produced. This may be necessary in a medium that is so complex technically and can encompass elements of so many others in its execution. This principle collaboration also extends to a shared notion of authorship that is inherent in the idea of play (p. 81). For us, both kinds of collaboration have been essential. As team leads, our backgrounds are in the arts and humanities. We have both spent many years in academic settings studying, working with, and teaching emerging technologies from artistic and scholarly perspectives. Our extended collaborative community includes programmers and engineers and students, as well as social and professional networks in the new media art, digital humanities, and computer graphics worlds. The audiences who play with our games bring to them very different expectations, depending upon the context in which they encounter them, and provide sometimes contradictory feedback. Gamers tend to want to play through very quickly, and to see any points values accumulate on a heads-up display. Artists tend to explore the game settings as virtual installations, and sometimes need prompting to move forward with in- game challenges. In our use of the videogame medium we strive to be legible to both the experienced gamer and the art patron, but most importantly, our goal is to produce a flare of awareness and recognition of how the "ludification of culture" manifests in everyday life, and to highlight the ways in which we co-produce its effects with our actions.

\section{Psychasthenia Studio}

It is this complex set of circumstances and concerns that animate our work in Psychasthenia Studio. In keeping with the hybrid critic-producer tradition, the Psychasthenia Studio games enact critique through gameplay. The series is not, however, about shutting down games as a communications medium, but rather activating it to a fuller potential. Most of our work in Psychasthenia Studio has been produced using the Unity3D game engine and has been shared both in the context of new media art exhibitions and demonstrations, either as a standalone experience or as part of a new media art exhibition, as well as through academic conferences and gatherings. While the focus of our team is on exploring videogame engines as a medium of expression, the work itself often takes on a distinctly dystopic edge, critiquing the ubiquity and power of games in contemporary culture, even as it uses game mechanics and conventions to explore its subjects.

Psychasthenia Studio is led by Joyce Rudinsky, a new media artist, and Victoria Szabo, a visual and media studies scholar. As noted earlier, we come from arts and humanities backgrounds, and work closely with programmers when needed for some aspects of implementation. The Psychasthenia series of games was begun as an experiment for the first Collaborations: Humanities, Arts \& Technology Festival in the North Carolina Research Triangle, which was held in 2010 in the University of North Carolina, School of Information and Library Science (UNCSILC). This regional festival was part of a conscious effort to bridge the arts and sciences and involved partnership with the North Carolina Renaissance Computing Institute ( $\mathrm{RENCl})$, a state organization dedicated to translating university computing research into other contexts, the University of North Carolina at Chapel Hill, Duke University, and North Carolina State University. RENCl provided resources and personnel to work with computational media technologies, including game engines and a virtual reality system, while members of the arts and humanities communities came together on experimental projects ultimately showcased at the CHAT Festival.

Our team adopted the theme of "psychasthenia" early on to describe the effects that their work produced. Psychasthenia is an archaic psychological term, and describes a condition characterized by "obsessions, compulsions, abnormal fears, and guilt and indecisiveness" (Comer, 2010, p. 97). The term is associated with the psychologist and philosopher Pierre Marie Félix Janet, who distinguished it from hysteria and described it as a fail- 
ure of the fonction du reél, or the function of the real, in Les Obsessions et la Psychasthénie (Janet \& Raymond, 1903). The term was fitting for our team's interest in the unstable boundaries between the real and the virtual, and the psychological effects of that ambiguity as they play out in videogames and the wider world. Jesper Juul has described the classic game model as "the game itself, the player's psychological relation to the game, and the relationship between the playing of the game and the rest of the world" (Juul, 2005, p. 197). This tripartite understanding of games and gameplay helps us articulate how we constructed situations that simultaneously participate in game conventions and draws the user's attention to them in the process of moving through the game. The following discussion will highlight each of these aspects as they relate to the three games being considered. Each game we developed in the 2009 ?2017 period reflects a moment in the evolution of the broader gamification discussion, as well as in what was possible with games-based new media art.

\section{Psychasthenia 1 (2010)}

The first Psychasthenia was a videogame installation that involved exploration of surreal landscapes and environments, as shown in Figure 1, while wearing a biometric sensor helmet in an immersive, $15^{\prime}$ virtual reality dome, as seen in Figure 2. Our production team all wore white doctor's jackets as they assisted users into the work, making the installation a performance as well as a VR-based experience. Moving through a curtain into a contained space, users waited their turns to put on a helmet and game controller, waiting to be guided through the experience. As the project description states:

Psychasthenia is an immersive artwork that operates allegedly as a psychological diagnostic environment, though actually functions as a mediation and critique on the twin phenomena of disempowered selfdiagnosis and the cultural pathologization of ordinary lived experience. The term psychasthenia, now deprecated in psychiatric literature, though still used in some therapeutic instruments, describes a neurotic state characterized historically by so-called mental weakness and lack of motive force. The irony of the piece is that psychasthenic symptoms pervade contemporary culture: we are all psychasthenics caught up in our own ills, real and imagined. The bewildering array of causes, theories, and cure the user encounters only heighten the sense of powerlessness diagnostics can provoke. (Psychasthenia 1, 2010)

Users answered psychological test questions based on the Minnesota Multiphasic Personality Inventory, though modified to suit the game's tone and slant. These were interspersed within increasingly abstract and fore-

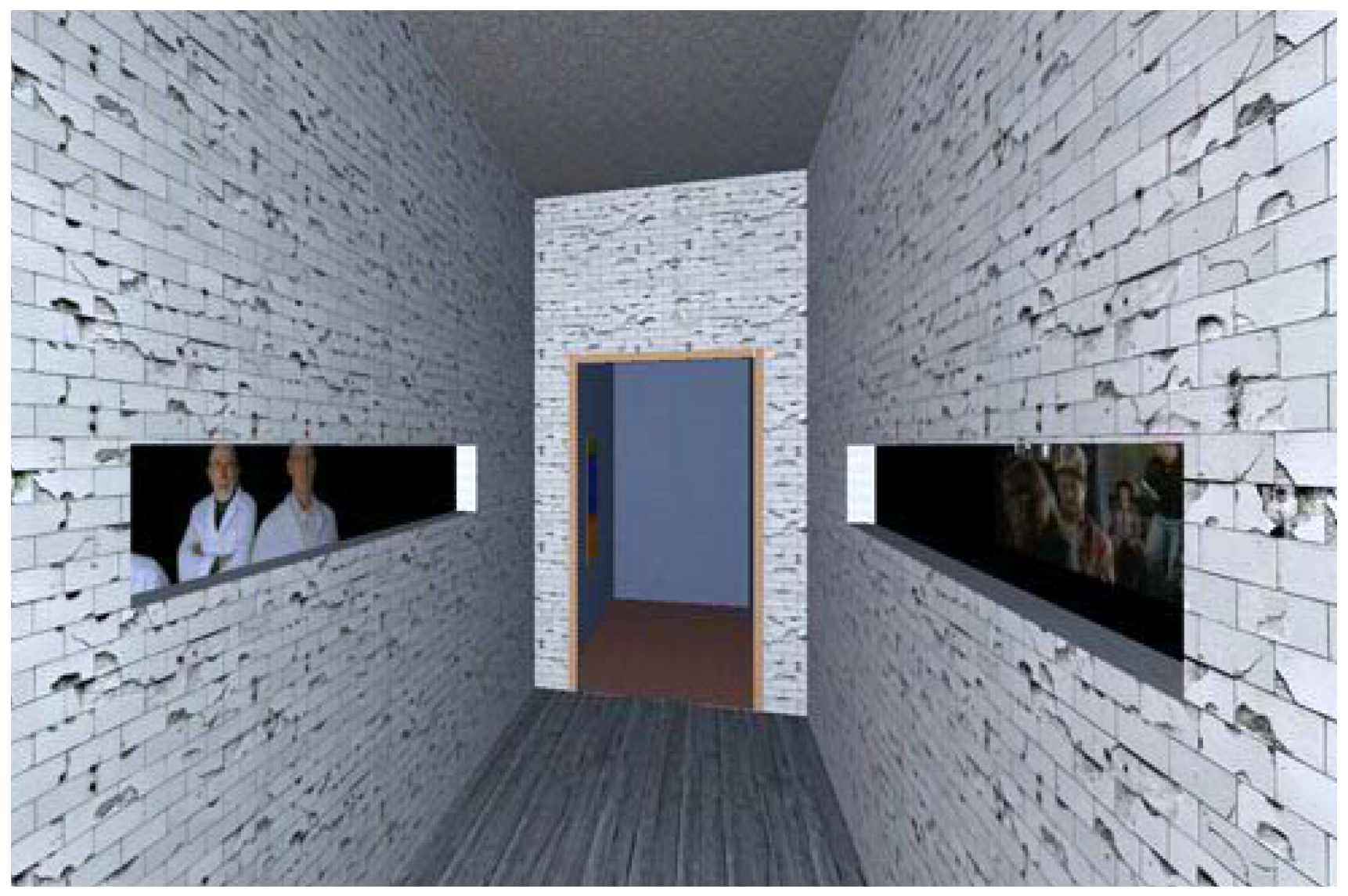

Figure 1. Still from Psychasthenia 1. Courtesy of the authors. 


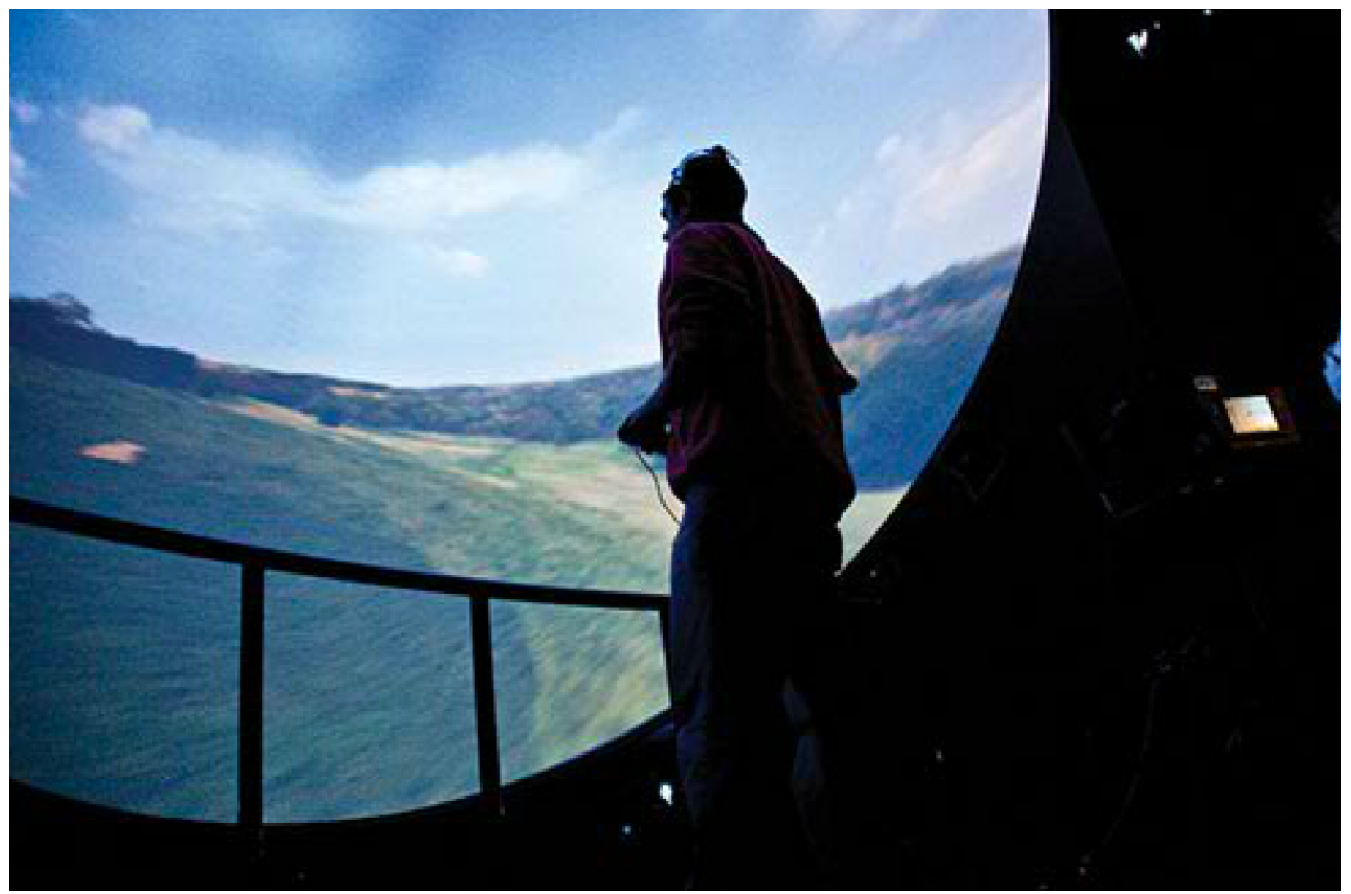

Figure 2. Still from Psychasthenia 1. Courtesy of the authors.

boding scenes, including claustrophobic tunnels, amorphous figures lurking in cells, and a twisting corridor peopled by grimacing patients subjected to galvanic facial contortions. After making it through the game world, which adapted to the head movements of the user by affecting lighting, tunnel size, and so forth, the user was inevitably "diagnosed" as suffering from "psychasthenia". The in-joke was that there was no way out; the enddiagnosis was an inevitable condition of participation. The question was merely how one arrived there, and how much worse the condition became over the duration of the experience of "diagnosis".

Perhaps the most notable feature of the installation was the extent to which people did not know how to respond to it. They could not tell if it was "real" or not. Users were hesitant to enter, some asking us if they needed to sign a disclaimer (we did not go so far as to require them to do so). They wondered aloud whether and how the sensor-helmet was having an influence on what they saw, and whether they were in danger of receiving shocks or other stimuli from it. This ambiguity may have been heightened by the fact that the piece was shown as part of a festival that was not only about new media art but also other innovative uses of technology, and by the then-novel technological apparatus used in the presentation, the VR half-dome. We also created the project at a time when the videogame America's Army (Mezoff) had just been updated as a first-person shooter on the Unreal engine in 2009, prompting substantial local discussion. As with America's Army, the fact that the game was used for both recruitment and training heightened a sense of ambiguity about how and why one would enter a "diagnostic" game space, and what those After Action Reviews might really be tracking.

\section{Psychasthenia 2 (2012)}

While Psychasthenia 1 diagnosed the malady, Psychasthenia 2 claimed to treat it as us exemplified by the doctor's office setting shown in Figure 3 , and the curative shopping spree undertaken by the user to meet basic needs, as shown in Figure 4. This project was introduced at the second CHAT Festival, at Duke University in 2012, as a standalone experience within a new media art gallery. We began the game with the goal of elaborating on concepts from the first piece, and by thinking though how to create a more tightly structured and coherent narrative experience that would push on the idea that game spaces could be used as treatment environments. Unlike the first game, this iteration was not dependent upon the immersive dome, and could be played without assistance. It shifted the conversation away from the idea that the game was pushing the user towards psychasthenic suffering in order to explore the idea of a gamified treatment regime. The game picks up where Psychasthenia 1 left off:

The "patient" entering the Psychasthenia 2 environment first encounters a classic video game orientation narrative, which provides contextualization on the user's role and overall experience in game play. The "patient" entering the installation learns upon entry into the system that he or she suffers from psychasthenia. He or she must then explore palliative measures keyed to Maslow's hierarchy of needs-physiological, safety, love/belonging, esteem, and self-actualization. These stages of self-actualization are organized as game levels to be mastered in order to win release from the asylum. The specific nature of the patient's 
pathology, refined by feedback from user input and in-game tracking, shapes his or her experience of the work, as well the options ultimately offered to maintain a tolerable existence.

After orientation the patient finds him/herself in a stark hospital room. With only a whirring fan for company, the patient begins the journey to selfactualization by exploring the opening environment using a video game controller. Soon he or she triggers their first encounter with Dr. Carl Abraham, the psychologist who will guide him or her through their journey to wellness. Dr. Carl appears in-world on a display screen in the patient's room. Throughout the installation he functions as a semi-omniscient, scientific analyst whose remarks simultaneously humanize the treatment process and suggest an uncanny alienation from human individuality. His opening remarks guide the patient toward the diagnosis room, a maze of file cabinets where the patient can find out more about his or her illness by exploring the resources available.

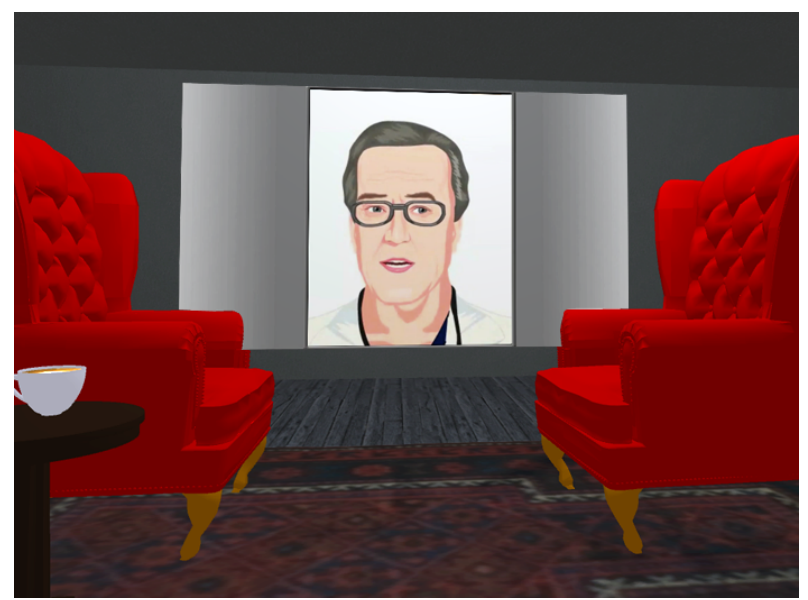

Figure 3. Still from Psychasthenia 2 website. Courtesy of the authors.

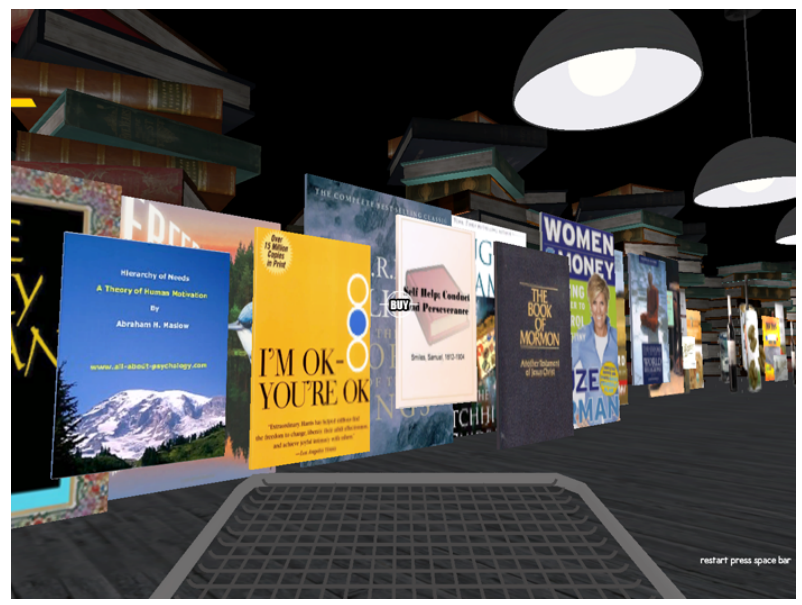

Figure 4. Still from Psychasthenia 2 website. Courtesy of the authors.
Soon the patient is led towards a computer terminal where the first round of testing will begin. At this point the journey begins with questions related to Maslow's "physiological" stage popping up to help refine the player's diagnosis and experience of the therapeutic "level" to follow. Now gameplay begins in earnest, as each game level corresponds to both a classic style of video game play and to a stage in Maslow's hierarchy. Dr. Carl introduces each level, following up with some questions tailored to the symptomology to be addressed. The physiology stage couples a shopping experience with exploration of an open-ended set of options. Basic biological needs met, the patient then progresses towards the "safety" stage where the patient must encounter his or her primal fears through the experience of killing various monsters that crop up on the way to treatment. The third stage, love/belonging, becomes a social challenge, with the patient determining which kinds of social relationships will best assuage their symptoms through interactions in a coffee shop. Social needs met, the patient next challenge is building up the esteem of peers, expressed here through workplace challenges set in an unusual office environment. Finally, self-actualization achieved, Dr. Carl sends the patient on his or her way, with admonitions to follow the treatment plan and an ominous warning that the door is always open for return.

Throughout the "game" levels the player always has the opportunity to examine contextual information about his or her illness, meta-commentary on psychasthenia itself, and imagery and other media which enriches the experience of any particular level in the "game". These elements, akin to the explanatory texts served in a quest-based game, serve both to deepen immersion in the gameworld mechanics and to frame the current challenges in historical and social contexts. Because the patient periodically encounters and answers additional questions relating to the specific nature of their "condition", the system is able to provide supplemental feedback tailored to their particular flavor of pathology. This aspect of the game experience is critical, because the installation is not just about one-way production of consumer subjectivity, but also about how algorithmic, participatory culture generates all-the-more compelling narratives of pathology in need of standardized routines of intervention. (Psychasthenia 2, 2012)

The idea for Psychasthenia 2 was predicated upon the emerging assumption that videogames could actually be beneficial, not just productive of darker human tendencies. We noted that arguments about the likelihood that they would produce violent behavior in adolescents were beginning to become more nuanced. As the American Psychological Association stated in a 2010 press release, "playing violent video games can make some adolescents more hostile, particularly those who are less 
agreeable, less conscientious and easily angered. But for others, it may offer opportunities to learn new skills and improve social networking". We wanted to explore this idea of the hidden power of videogames, for good or for ill. This was simultaneously alarming and reassuring. Kids with the right OCEAN 5-factors personality attributes (Openness, Conscientiousness, Extraversion, Agreeableness, and Neuroticism) would be fine, while others might be made worse (American Psychological Association, 2010). At the same time, books like What Videogames Have to Teach Us About Learning and Literacy by James Paul Gee (2007) explored cognitive development through games, providing some nuance and valorization of a previously denigrated medium.

The game elements included here also reflect thencurrent discourse around gamification, as noted earlier. In Psychasthenia 2 we included digital badges, for example, to track progress in-game. Users navigating the social level had to pick up badges for love and belonging, family, and religion before they could proceed to the next level of the self-actualization journey. The badge categories themselves reflected what we called, using intentionally esoteric language, a "palliative measure", or treatment strategy, that had been prominently cited in the nineteenth and early twentieth-century literature about psychasthenia, drawing upon the work of William James, Carl Jung, Janet, and others for inspiration. The character of Dr. Carl Abraham, who appears on a video screen

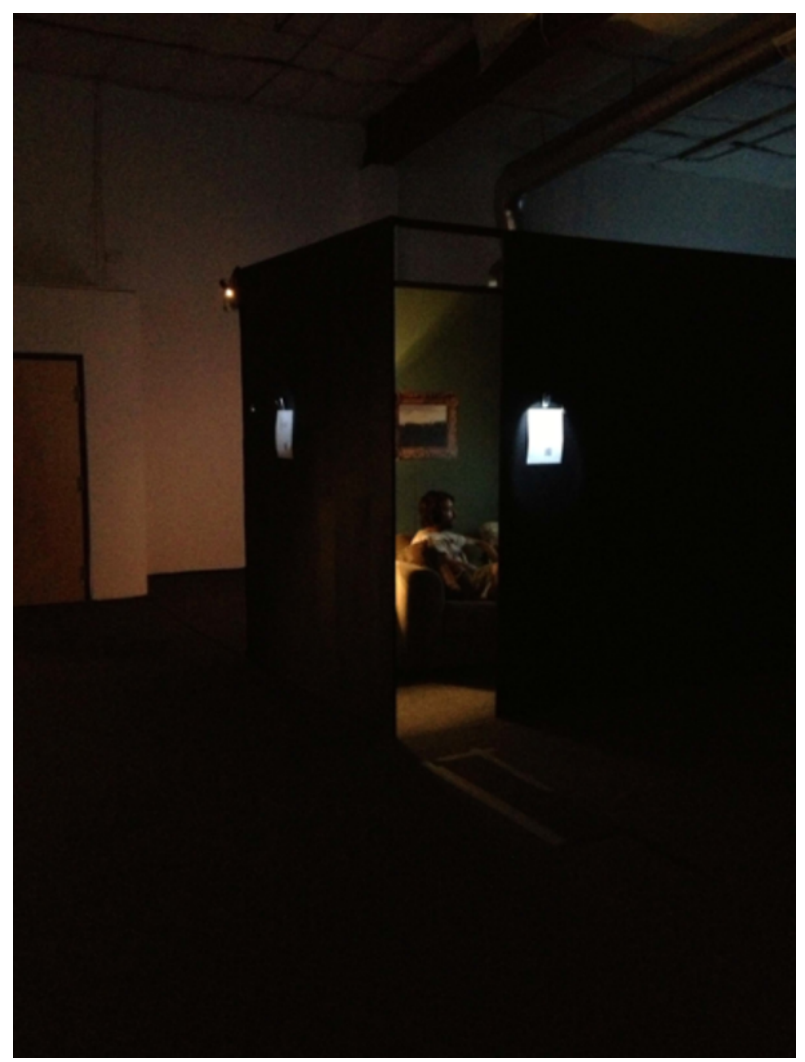

Figure 5. Installation photo from Psychasthenia 2 website. Courtesy of the authors. as a rather overbearing guide in the user's psychic journey, refers both to Carl Jung and Abraham Maslow, and also to the then-current fad for virtual assistants, that is animated chatbots, here generated from Voki bots with animated elements.

The other notable aspect about Psychasthenia 2 for us was that it was well received as new media art. It was selected for the Currents New Media Festival in 2013, where it was installed in its own "doctor's office" (Currents, 2013). At Currents it was set up as an online diagnostic and treatment environment, with its own separate cubicle, complete with a doily-covered couch, a floor lamp, and wall art taken from scenes in the game itself (Figures 5 and 6). All of these props were designed to blur the boundaries between the 3D game space and real life. The user reclined on the couch and uses an ordinary game controller to navigate the system in privacy, interacting with Dr. Carl throughout the journey to selfactualization. In this way we moved from the futuristic setting of the VR half-dome and into a semi-plausible treatment environment that invoked an individual therapist's office.

Psychasthenia 2 was shown in other juried new media venues as well. This acceptance of the work as new media art was a breakthrough for us, in that the first piece, Psychasthenia 1 was understood and appreciated more as a technological experiment than as an artwork in itself. It required a specialized setup and

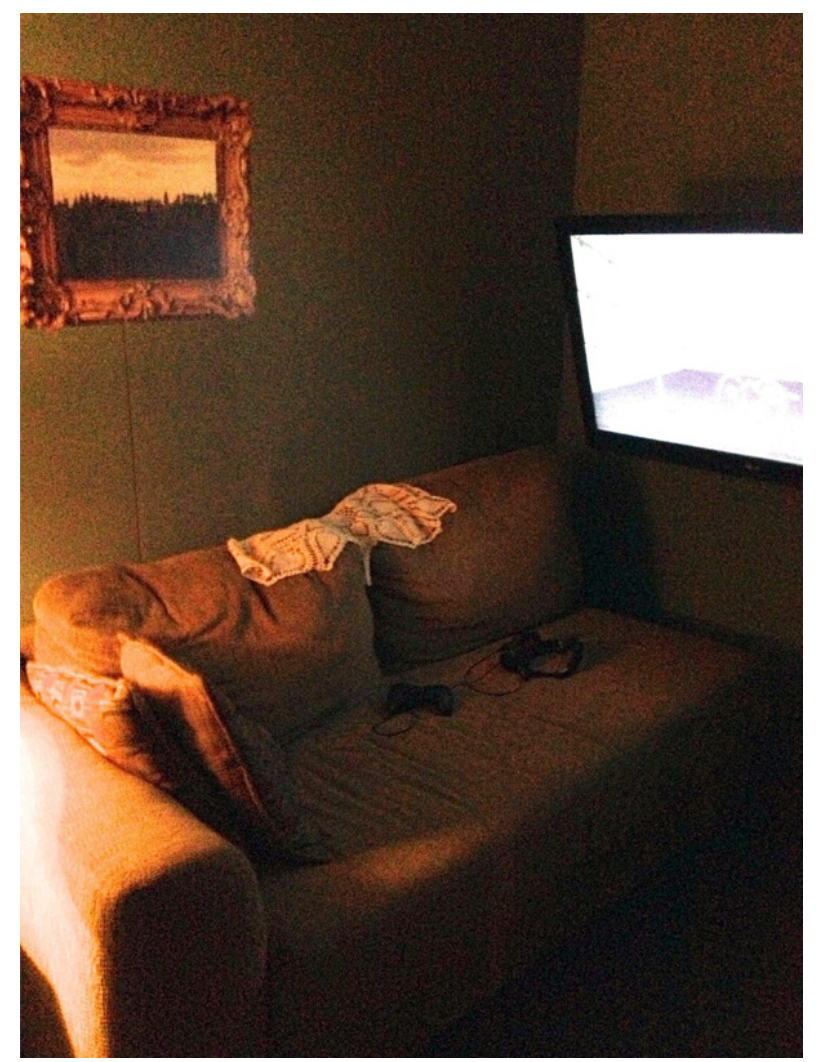

Figure 6. Installation photo from Psychasthenia 2 website. Courtesy of the authors. 
equipment and relied upon us as presenters to complete its performance of gamified psychological diagnosis. However, it also did not fit game venues where high powered graphical innovations or sophisticated algorithms might have lent it more legitimacy. The innovation was in the creative use of game engines, not the extension of the technology itself. With this piece, we wanted to create something that could operate easily as a new media art installation without specialized knowledge or assistance. We wanted the technology to become more naturalized into the experience and did so by relying on the similarity between the couch of the traditional therapist's office and that of the at-home gamer.

Ultimately, Psychasthenia 2 was designed as a commentary on what constituted self-actualization, at the same time as it asserted its status as an optimal tool for personal growth. At the same time, the ongoing withering commentary from "Dr. Carl" helped establish it as satire; self-actualization culminating in a formless afterlife, with a hint of reincarnation into the same awful coil implied by the game's restart mechanism. In this we strove to highlight the difference between the typically low stakes of the computer game world and those of everyday life.

\section{Psychasthenia 3: Dupes (2017)}

Psychasthenia 3: Dupes took the advances we had made with Psychasthenia 2 as an art intervention further, continuing the theme of paralleling gameplay with lived experience in gamified everyday life, as takes place, for example, in the workplace breakroom environment shown in Figure 7. We also brought back some of the genre ambiguity of the Psychasthenia 1 dome-based performance by creating games within games, where it is unclear where the boundaries lie, or the subject-position of the user within that system.
Psychasthenia 3: Dupes is ultimately about how we can retain awareness of the narrow-casted nature of our everyday lives in the face of ubiquitous data-collection, analysis, and digital remediation of everyday life (Psychasthenia 3: Dupes Trailer, 2017). The game draws upon challenging workplace relationships and gamified assessment environments, revealing the ubiquity of data shadow construction, the erosion of personal privacy, and the amplified power of the external instantiation of an avatar self. We set it in a dystopic, yet banal, workplace office setting, where every interaction, whether "in person" or online, is logged and judged against a series of internal evaluation factors. These success factors are in turn revealed at the end of the game in the form of a comprehensive Success Report, which resembles a credit report in its presentation and measures, and which forecasts your ultimate workplace fate.

The seeming premise of the game is that the user must complete an HR personality test before the end of a game-world workday. However, the user is continually interrupted with other demands. Just as the user settles into the test, a notification screen pops up on the virtual computer. This begins a sequence that repeats throughout the day-a series of interruptions as you complete your quest...to finish the quiz. Over the course of the day the user visits the company shrink, attend a staff meeting, stop by the communal water cooler, and is summoned for a meeting with the boss, following by a dispiriting trudge back to a lowly basement cube. During these side trips, the user's interactions with archetypal co-workers are secretly logged, the interactions themselves ultimately playing a critical part in building up the "success" profile revealed at the end of the game.

Like Psychasthenia 1 and 2, in which we used an altered version of the Minnesota Multiphasic Personality Inventory to "diagnose" and "treat" the user's condition, Psychasthenia 3: Dupes is structured around a psycholog-

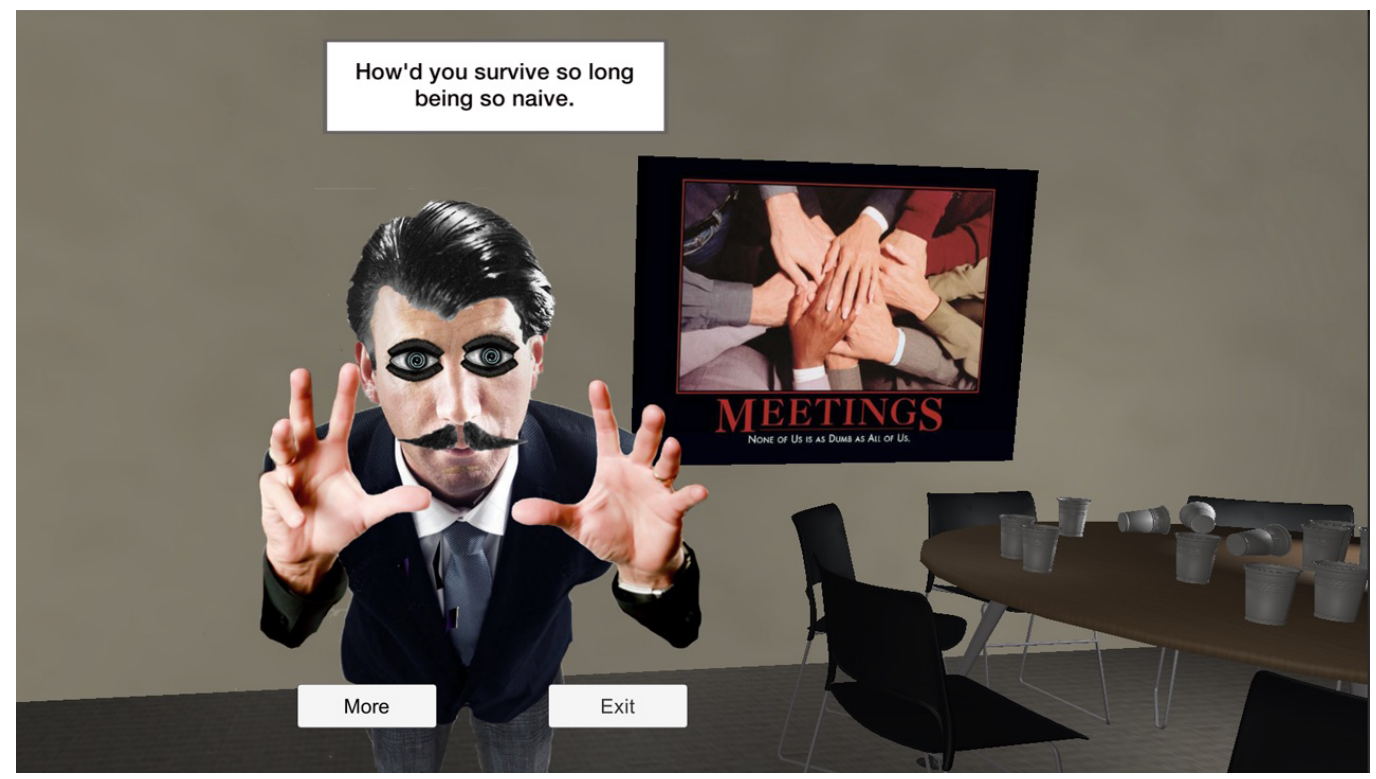

Figure 7. Still from Psychasthenia 3: Dupes. Courtesy of the authors. 
ical test. Here the overt action of the game is based on popular OCEAN test's Five Factors of Openness, Conscientiousness, Extraversion, Agreeableness, and Neuroticism. They are re-imagined within the context of the workplace "Success Index" as Gullibility, Grinding, Gladhanding, Subjugation, and Internalization. The questions the user is to attempt to answer throughout the day correspond to these categories.

We designed each character encountered within the game to reflect a different workplace archetype: The Psychotic, The Artiste, The Narcissist, The Celebrity, The Sophist, The Bombast, The Charismatic, The Dominator, The Ingenue, The Shopper, the Sycophant, the Melancholic, and the Egoist. Interactions with each character reveals his or her core attributes, with the user's possible responses becoming increasingly limited as the day goes on. Declining the engagement is not an option, and user responses to character interactions factor into the ultimate HR test results, as does a Collusion score based on the length of interaction with each. The characters the user interacts with are 2D poster collages rather than "realistic" 3D figures, and the user's size and location vary based on responses to their characters-all qualities adding to the destabilization of any realist assumptions one might bring to the game. During the endgame, these archetypal figures recombine into a modern-day Tarot, augmenting and illuminating the Success Index ostensibly compiled from the formal test.

The system reveals the characters representing the user's Spiritual Twin and Nemesis, as shown in Figure 8, as well as numerical Success Index broken down with pie charts, as shown in Figure 9, and a final Fate card. The

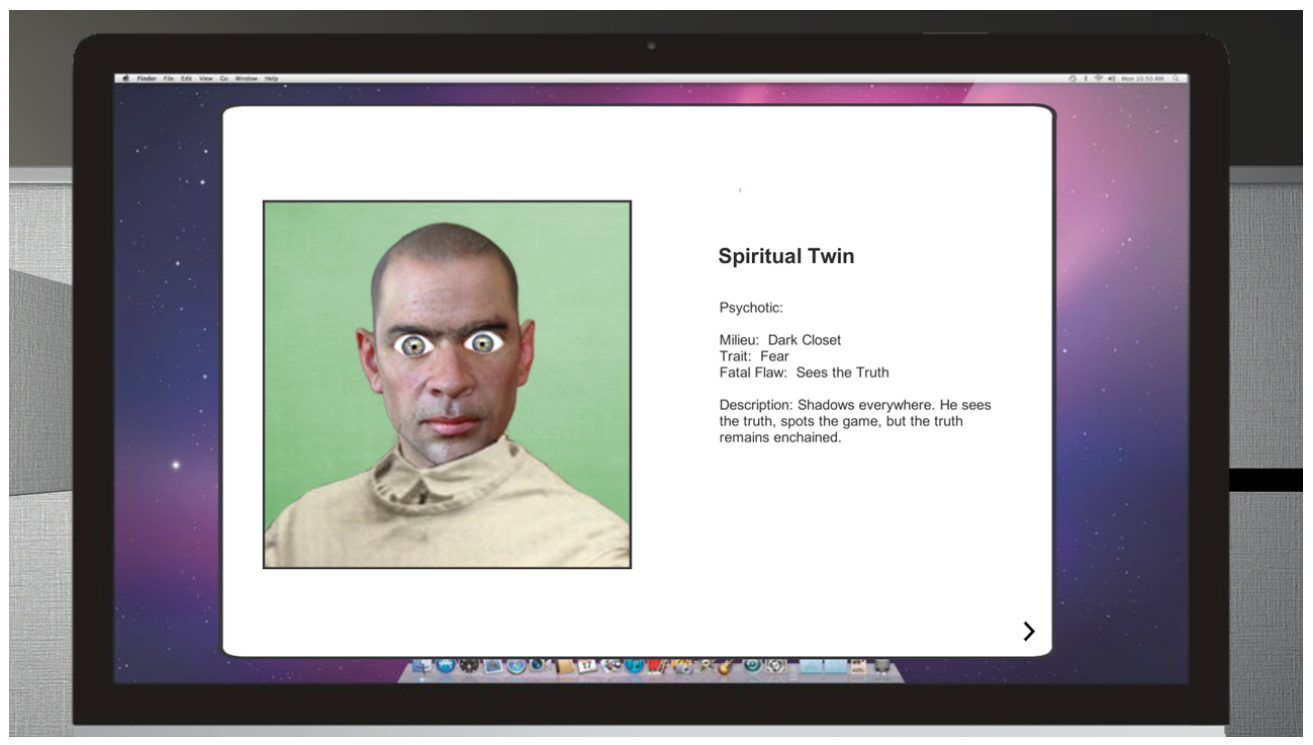

Figure 8. Still from Psychasthenia 3: Dupes. Courtesy of the authors.

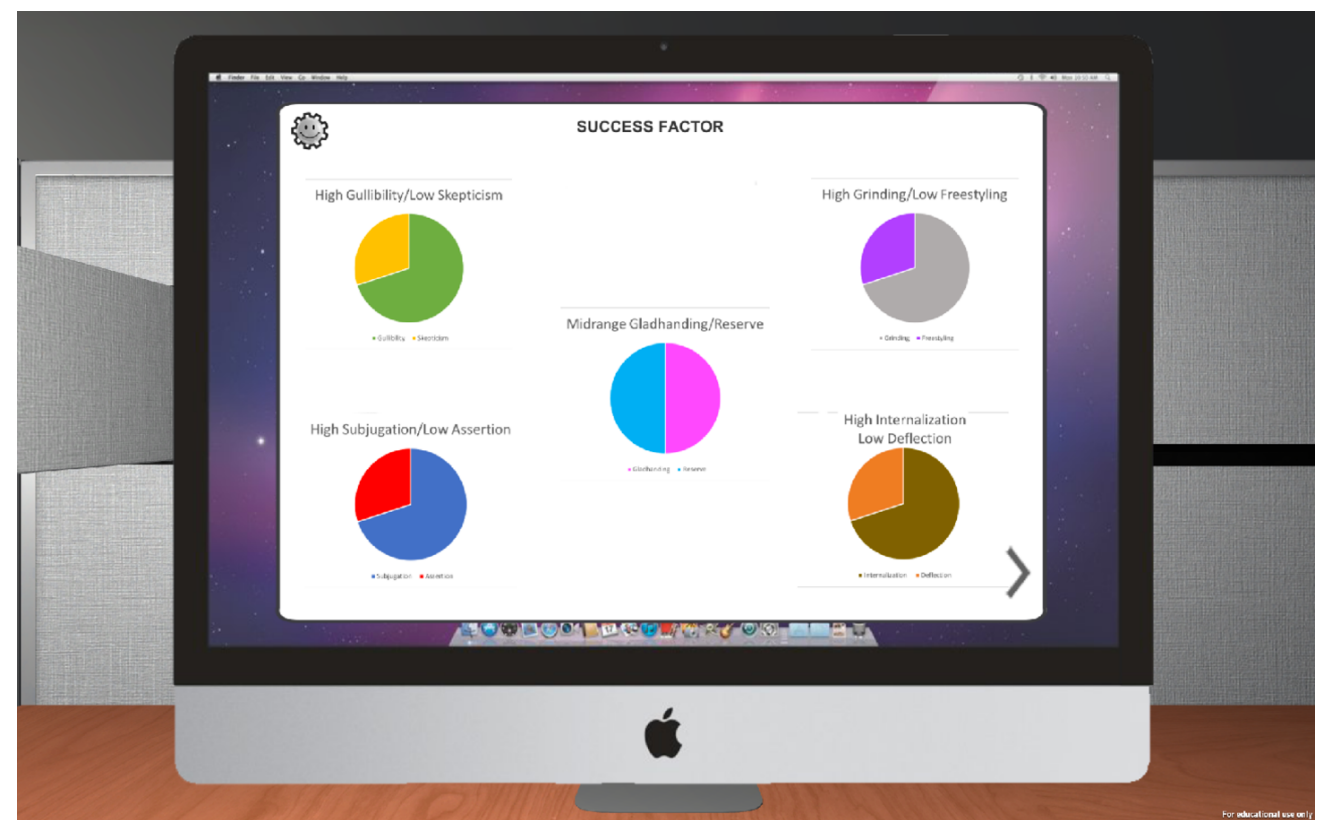

Figure 9. Still from Psychasthenia 3: Dupes. Courtesy of the authors. 
Tarot allusion is both a reference to the 19th century occultism that existed alongside some of the foundational elements of modern psychology, and a commentary on the legitimacy of the measurement instruments we deploy today.

We designed the user's experience of the game to conflate the relationship between the individual playing a game and everyday work life. The game begins with the sound of coffee pouring into a cup. The screen fades in to reveal an empty computer monitor, in-world in what appears to be a standard office cubicle. A digital clock advances. Gameplay only begins with the movement of the mouse. This simple choice establishes kinesthetically a relationship that we strive to exploit throughout gameplay-the blending of the experience of playing the game with the action you are taking in our fictional world.
When at the keyboard in the cube, the game user clicks on submit buttons to interact with the screen. This is a deliberate counterpoint to the current trend of increasingly immersive videogames, from the Wii onward, that use motion tracking, VR headsets, force feedback controllers, and other tools to effect changes of perspective. In a moment that feels more akin to using Windows Remote Desktop to get into a workplace admin system but is actually the logical conclusion of fully-formed VR simulation of everyday life, the game player and the avatar are united in purpose and experience.

In Psychasthenia 3: Dupes we reflect the preoccupations of gamified internet culture in several ways relevant to its 2017 debut. The pompous doctor's innovative "new method" resembles nothing so much as a Buzzfeed quiz (see Figures 10 and 11). Several of the subsequent char-

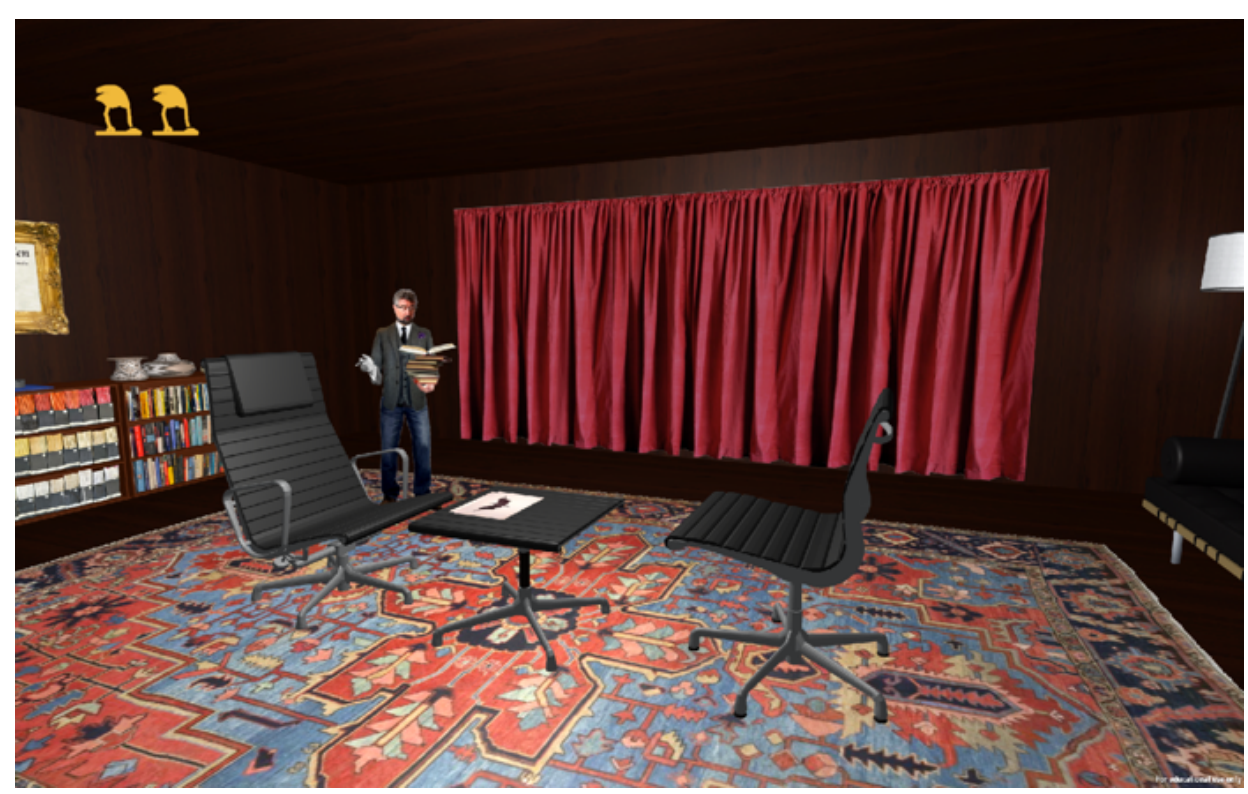

Figure 10. Still from Psychasthenia 3: Dupes. Courtesy of the authors.

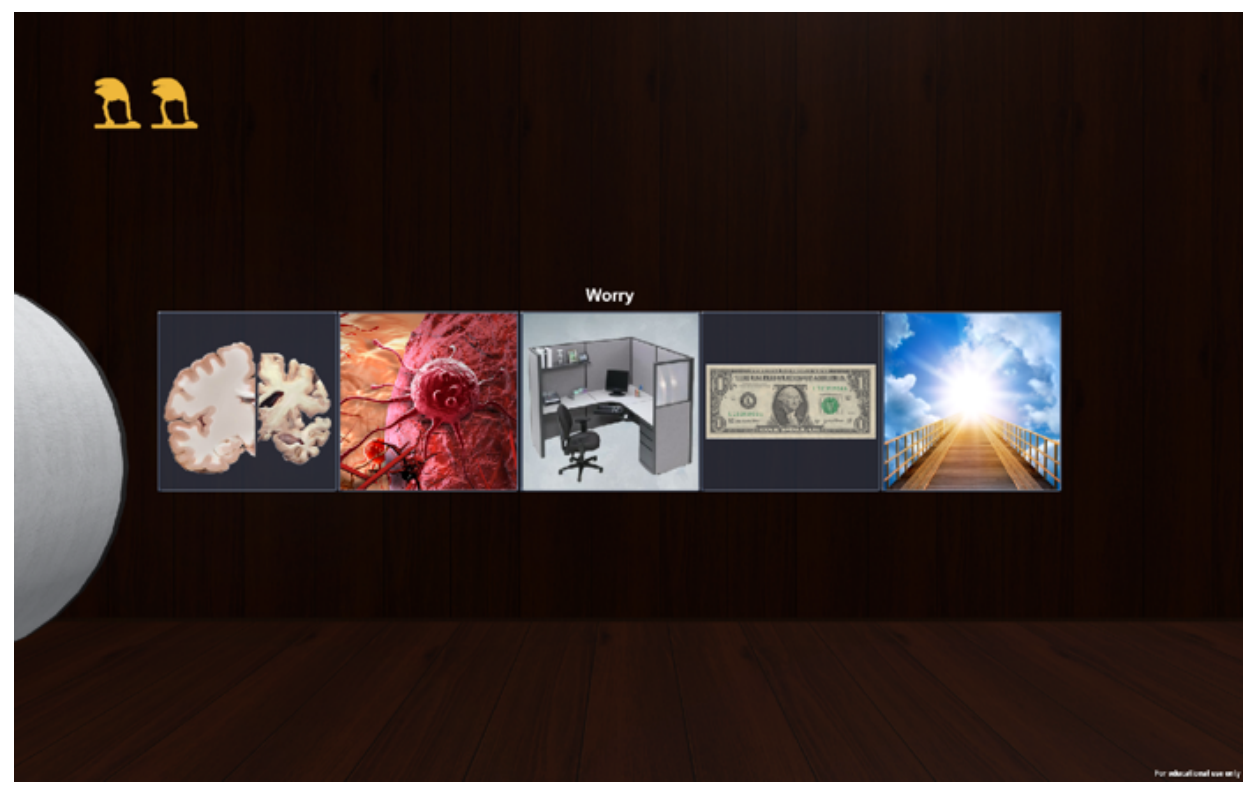

Figure 11. Still from Psychasthenia 3: Dupes. Courtesy of the authors. 
acters reflect gamified social media types: the Celebrity proudly aggregating hearts in response to an increasingly disturbing set of selfies; the Narcissist equating his low resting heartrate with personal excellence; the Bombast spouting nostrums modeling on a nonsensical text generator as an approving glow accumulates around her from the watching fans. The conference room, meanwhile, is decorated with carnivorous predators gleaned from image searches, and the breakroom is filled with mock "Successories", as found in popular internet memes. The boss' office is adorned with badges, and the user's showdown with him includes his spittle splattering the view-screen, a reference to boss-level battles in Massively Multiplayer Online Role-Playing Games (MMORPGs).

In this game we strove to reveal gradually the estrangement of the holistic individual from authentic human experience. This conclusion is predicated on the assumption that nothing within the workplace remains out- side the evaluation system. And, as the wide-ranging nature of the avatar interactions suggests, not much outside of that system exists at all. This "human" indirection within the game reveals the extent to which a gamified, logged quotidian experience becomes subject to exploitation and summary judgements re-appropriated into an evaluation matrix. Only the Psychotic, the conspiracy theorist who warns of constant surveillance, truly knows what is going on. By the time the workday ends, and you've found yourself back in your basement cubicle picking up your test results, you've already Accepted the End User License Agreement (EULA) proffered by your Dominator of a boss (see Figure 12) and are presumably resigned to whatever Fate the system personified by Dr. Carl declares appropriate, as shown in Figure 13.

Like Psychasthenia 2, we are presenting Psychasthenia 3: Dupes both in academic conference settings and demos, and as a new media art installation. It was se-

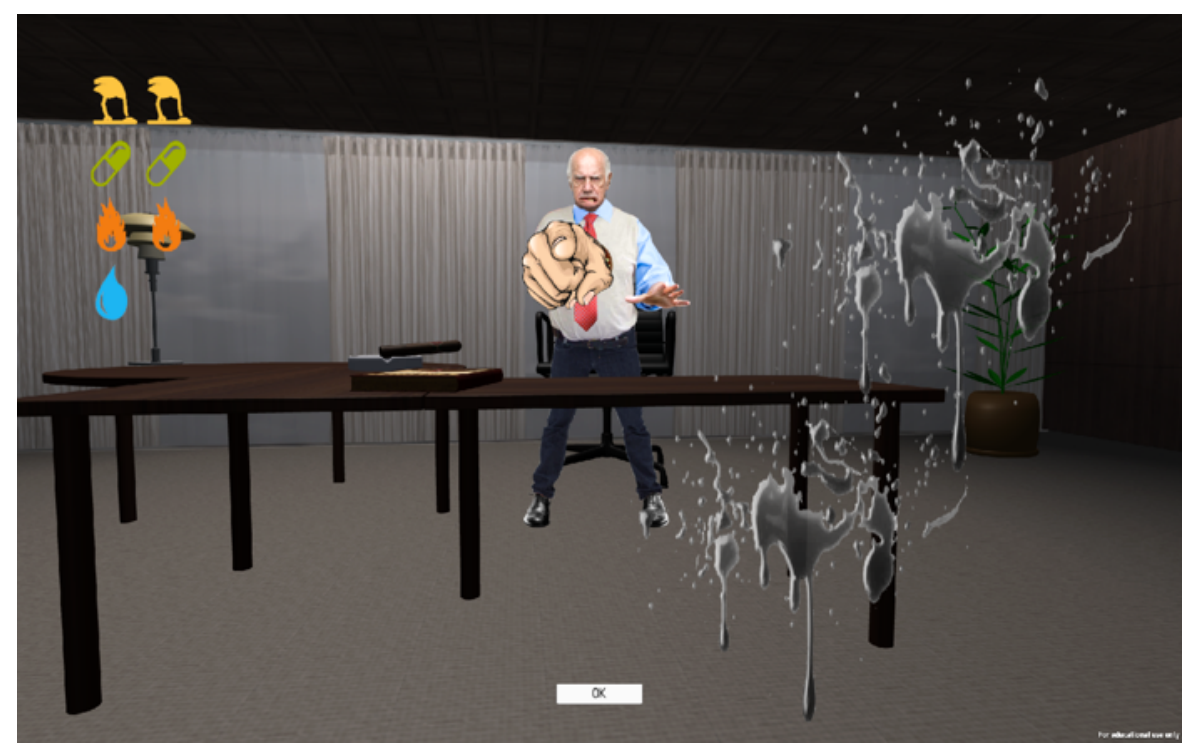

Figure 12. Still from Psychasthenia 3: Dupes. Courtesy of the authors.

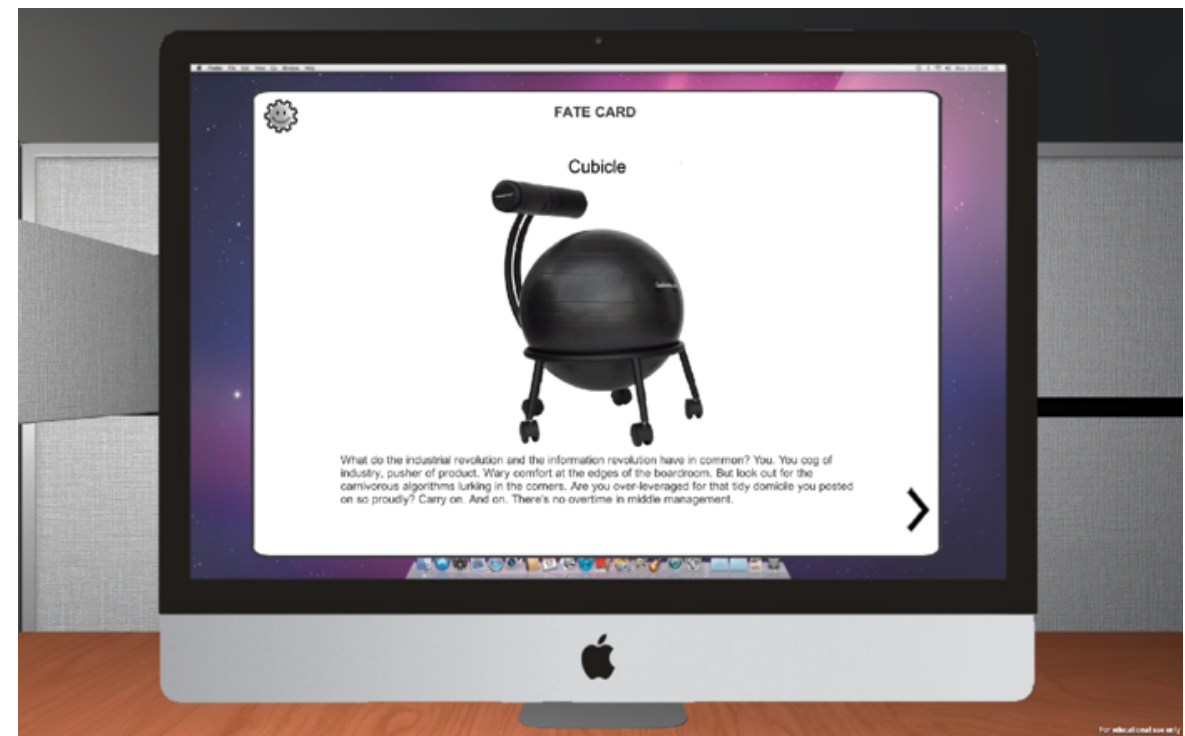

Figure 13. Still from Psychasthenia 3: Dupes. Courtesy of the authors. 
lected for the Future Perfect show connected to the annual Symposium on the Sciences and the Humanities: Intersections, Methods, Examples, for example. This positioning marks it as an example of new media art produced in an academic context (Future Perfect, 2018). The fully installed version of the game is designed to look like a dingy cubicle in the middle of the art gallery space. The purpose of this juxtaposition is to highlight the constructed nature of our workday lives, to make visible the moment in which we are operating, where we travel to virtual cubes in order to do an HR test on a midrange computer terminal. Unlike Psychasthenia 2, which presented itself in a kind of doctor's office setting, in its fully installed form Psychasthenia 3: Dupes masks its intervention in a regressive series of windows not unlike what you see when you mirror back your own screen in a videoconference. It should be unclear to the user if they have wandered out of the gallery by mistake, and this game, unlike the others, will be available for download, potentially "dangerously" decontextualized for the unwary.

We produced Psychasthenia 3: Dupes in the context of a culture of increasing awareness of how surveillance and tracking technologies saturate our everyday lives, often with our consent, implicit or explicit, in exchange for the opportunity to communicate, shop, and research, both online and in the physical world. Bit by bit we accrete avatar or shadow-selves online, our avatar identities. Such federated identities both make our online lives easier and help shape the golem. This convergence of game culture and avatar-identity-formation manifests in the latest technologies being developed by social media, as noted earlier. This amalgam of these two elements - the rise of videogame culture and the coincident development of our data shadow avatar identities within the context of online media-emerged as an important critical focus for this game.

User response to the game so far indicates that we are succeeding in getting our goals across. One lingering concern we have is that after some users play through they tell us it is "depressing" and "true ". We also use humor and creative visual efforts in our work, and hope that the relative simplicity of the game mechanics makes it easy to continue on, but also worry about losing the fun and playfulness of games. Perhaps in this way we are experiencing in the creation and reception of own work the tension between games and gamification, as well as the challenges designers of "serious games" encounter. As Alex Galloway has written of social realist games, Psychasthenia Studio games highlight the "congruity" between quotidian lived experience and the games themselves (p. 71), and to the extent that they are about the nature and consequences of gamification itself, they fall into that category. Ultimately, the goal of our work of Psychasthenia Studio is both to expose the workings of gamification in everyday life, and to explore how the affordances of game platforms can be activated by critical and creative artists.

\section{Conclusions}

This essay has described how emerging real-world gamification practices in education, industry, the military, and mass communications are reflected and critiqued in the artist's games we produced in the Psychasthenia Studio series. We consider the work of Psychasthenia Studio to be part of a transitional stage for games as art. The work is about the medium, and the message that the medium conveys. The Psychasthenia games have taken up Galloway's challenge in that they disrupt the relationship of the game to the world, and implicitly critique gameplay through the addition of intentional constraints. As Walz and Deterding (2014) ask, "What are the ethical ramifications of a societal panludicum-for policy makers, for designers, but also for individuals alternatively extending or replacing our will with technically mediated systems of goals?" (Walz \& Deterding, 2014, p. 11). We intend for the work to function as an early warning system, pointing towards increasingly normalized-and sometimes uncritical-cultural shifts towards gamification and avatar-identities.

We hope that the Psychasthenia series, in its reflexive interest in gamification as a cultural phenomenon, helps point the way towards a more conscious appropriation, subversion, and transformation of emerging media trends related to games and gamification. The pervasive gamification of contemporary culture calls for much more critical response, as has been demonstrated in the growth of both game studies and the study of gamification as a cultural phenomenon. Over the years, our users have been surprisingly susceptible to believing the Psychasthenia Studio games are legitimate psychological tools, rather than satiric art, as noted earlier. As the game creators, this both delights and alarms us. This ambiguity may exist in part because of the uncertain stance of videogames in the art world, and in part because the games perform a kind of scientific legitimacy with their reliance on new media technologies. However much we may appreciate the effect as artists, this user credulousness is also worrying. The very plausibility of such gamified experiences as the next stage of cyber-human development suggests that even as we consider ways to use games to improve education, productivity, and communications, we also need to build up in diverse audiences a correspondingly robust culture of media literacy, reflection, and critique around their production and use.

Further, as Psychasthenia 3: Dupes hints at, and as the progression of the games' preoccupations suggest, concerns over the impact of videogames on society have given way to more complex engagements with the medium, and of gamification more generally. A decade ago, in "Countergaming", Alex Galloway issued a challenge to create avant-garde games, that involve "radical action" and a critique of gameplay itself. He suggests that they "should reinvent the architectural flow of play and the game's position in the world, not just its map and characters" (Galloway, 2006, p. 125). The stakes 
Galloway outlined are ever higher as the field of gameplay and gamification expands. Longstanding anxieties over the social effects of videogames have been joined with worries about, and speculations over, a wider range of computational media forms that increasingly interest the worlds of games and gamification: social media, filter bubbles, and artificial intelligence agents. These topics, along with deeper engagement with the potential of mixed and augmented reality systems to make the whole world a game, will likely animate our Psychasthenia Studio work on the next iteration of the series.

\section{Acknowledgments}

Thanks to my collaborator Joyce Rudinsky from the University of North Carolina, Chapel Hill, USA and our partners in Psychasthenia Studio.

\section{Conflict of Interests}

The author declares no conflict of interests.

\section{References}

American Psychological Association. (2010, June 10). Violent video games may increase aggression in some but not others, says new research [Press release]. Retrieved from https://www.apa.org/news/press/ releases/2010/06/violent-video-games.aspx

Bogost, I. (2014). Why gamification is bullshit. In S. P. Walz \& S. Deterding (Eds.), The gameful world: Approaches, issues, applications (pp. 65-79). Cambridge, MA: MIT Press.

Comer, R. J. (2010). Abnormal psychology. New York, NY: Palgrave Macmillan.

Currents. (2013). Currents new media 2013. Retrieved from www.currentsnewmedia.org/festivals/ currents-2013

Deterding, S., Dixon, D., Khaled, R., \& Nacke, L. (2011, September). From game design elements to gamefulness: Defining gamification. Proceedings of the 15th international academic MindTrek conference: Envisioning future media environments ( $\mathrm{pp}$. 9-15). New York, NY: ACM. doi:10.1145/2181037.2181040

Flanagan, M. (2009). Critical play: Radical game design. Cambridge, MA: MIT Press.

Galloway, A. R. (2006). Gaming: Essays on algorithmic culture. Minneapolis, MN: University of Minnesota
Press.

Gee, J. P. (2007). What videogames have to teach us about learning and literacy. New York, NY: Palgrave Macmillan.

Graham, L. (2017, June 7). Apple's new software is a game changer for augmented reality, experts say. CNBC. Retrieved from https://www.cnbc.com/ 2017/06/07/apple-arkit-software-game-changer-foraugmented-reality-ar-tech-say-experts.html

Janet, P., \& Raymond, F. (1903). Les obsessions et la psychasthénie [The obsessions and the psychasthenia]. Paris: F. Alcan.

Juul, J. (2005). Half-real: Video games between real rules and fictional worlds. Cambridge, MA: MIT Press.

Kaplan, D. (2015, March 15). Facebook, oculus and the future of virtual reality. Tech Crunch. Retrieved from https://techcrunch.com/2015/03/15/facebook-oculus -and-the-future-of-virtual-reality

Kapp, K. M. (2012). The gamification of learning and instruction: Game-based methods and strategies for training and education. San Francisco, CA: Pfeiffer.

Lowood, H. (2014). Video capture: Machinima, documentation, and the history of virtual worlds. In $\mathrm{H}$. Lowood \& M. Nitsche (Eds.), The machinima reader (pp. 3-22). Cambridge, MA: MIT Press.

McGonigal, J. (2011). Reality is broken: Why games make us better and how they can change the world. New York, NY: Penguin Press.

McGonigal, J. (2015). SuperBetter: A revolutionary approach to getting stronger, happier, braver, and more resilient. New York, NY: Penguin Press.

Psychasthenia 1. (2010). Psychasthenia 1. Psychasthenia immersive 3D artwork. Retrieved from http://www.psychasthenia-studio.com/psych.html

Psychasthenia 2. (2012). Psychasthenia 2. Psychasthenia immersive 3D artwork. Retrieved from http://www. psychasthenia-studio.com/psychasthenia2.html

Psychasthenia 3: Dupes. (2017). Psychasthenia 3: Dupes trailer. Psychasthenia immersive 3D artwork. Retrieved from https://vimeo.com/235995669

Raessens, J. (2006). Playful identities, or the ludification of culture. Games and Culture, 1(1), 52-57.

Sharp, J. (2015). Works of game: On the aesthetics of games and art. Cambridge, MA: MIT Press.

Walz, S. P., \& Deterding, S. (2014). An introduction to the gameful world. In S. P. Walz \& S. Deterding (Eds.), The gameful world: Approaches, issues, applications (pp. 65-79). Cambridge, MA: MIT Press.

\section{About the Author}

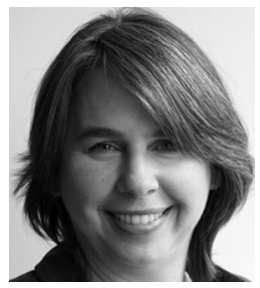

Victoria Szabo is Associate Research Professor of Visual and Media Studies at Duke University. In addition to her collaboration with Psychasthenia Studio, she is the founding Director of Graduate Studies for the PhD in Computational Media, Arts \& Cultures, and partners in the Wired! Lab for Digital Art History \& Visual Culture on Visualizing Cities projects. She is also Director of the Information Science + Studies Program. She has a PhD in English from the University of Rochester, USA. 